\title{
Viscometric Studies in Dilute Solution Mixtures of Chitosan and Microcrystalline Chitosan with Poly(vinyl alcohol)
}

\author{
Katarzyna Lewandowska
}

Received: 15 October 2012/Accepted: 20 March 2013/Published online: 15 August 2013

(C) The Author(s) 2013. This article is published with open access at Springerlink.com

\begin{abstract}
The viscosity behavior of aqueous mixtures formed by a polyelectrolyte (A) and a neutral polymer (B), such as chitosan/poly(vinyl alcohol) (Ch/PVA) and microcrystalline chitosan/poly(vinyl alcohol) (MCCh/PVA), have been investigated at $25{ }^{\circ} \mathrm{C}$. The intrinsic viscosity and the viscosity interaction parameter of each polymer in $0.1 \mathrm{~mol} \cdot \mathrm{dm}^{-3}$ $\mathrm{CH}_{3} \mathrm{COOH} / 0.2 \mathrm{~mol} \cdot \mathrm{dm}^{-3} \mathrm{NaCl}$ solution as well as the ternary systems (polymer A/polymer $\mathrm{B} /$ solvent) have been determined and have served for estimation of the miscibility of different polymer mixtures by means of the method of classical dilution. By comparing the experimental and ideal viscosity data it is clearly seen that the satisfaction of the miscibility criterion depends on the definition of the ideal parameter $b_{\mathrm{m}}^{\text {id }}$. If the $b_{\mathrm{m}}^{\mathrm{id}}$ parameter is defined according to the Krigbaum-Wall criterion and Garcia criterion, the investigated blends of Ch/PVA satisfy the miscibility criterion. In the case of MCCh/PVA blends, the polymeric components show poor miscibility. Additionally, the viscosity results show that the degree of miscibility depends on the molecular weight of chitosan and on the degree of PVA hydrolysis.
\end{abstract}

Keywords Chitosan · Polymer blends · Miscibility · Poly(vinyl alcohol) · Interaction parameter $\cdot$ Miscibility criteria $\cdot$ Intrinsic viscosity

\section{Introduction}

The physico-chemical properties of high molecular weight compounds can be modified by various methods, one of them is simple blending with other macromolecular compounds,

Electronic supplementary material The online version of this article (doi:10.1007/s10953-013-0053-3) contains supplementary material, which is available to authorized users.

K. Lewandowska ( $\square)$

Faculty of Chemistry, Chair of Chemistry and Photochemistry of Polymers, Nicolaus Copernicus

University, 7 Gagarin Street, 87-100 Toruń, Poland

e-mail: reol@chem.umk.pl; reol@chem.uni.torun.pl 
which assures the required useful behavior in manufacturing and applications. In this study a natural polysaccharide, chitosan (Ch), has been blended with poly(vinyl alcohol) (PVA). $\mathrm{Ch}$ is a modified natural polymer, that is non-toxic, bioactive and biodegradable, derived by deacetylation of chitin. It is the second most widespread biopolymer in nature after cellulose [1,2]. This biopolymer is a weak polybase, showing a polyelectrolytic effect in aqueous dilute acidic solution. Specific properties of Ch have resulted in an increasing interest in its investigation and application, e.g. in medicine, pharmacy and the food and cosmetic industries [3,4]. The growth in practical applications for this natural polymer is related to the modification of its properties through suitable changes of molecular, supermolecular and chemical structure. Microcrystalline chitosan (MCCh) is a special form of $\mathrm{Ch}$, which is prepared via its physicochemical modification using aqueous hydroxides and their salts [5, 6]. A previous study [7] showed that the thermal properties of films produced by blending $\mathrm{Ch}$ and PVA depend on the degree of hydrolysis of PVA and on the molecular weight of $\mathrm{Ch}$. To my knowledge the physico-chemical properties of MCCh with PVA mixtures have not been investigated before. In the present work, the miscibility of Ch/PVA and MCCh/PVA have been studied by viscometry. One of the procedures used for the estimation of miscibility in dilute solution is the determination of viscosity interaction parameters for mixtures of polymers in different proportions. This method is often used because of its simplicity and low cost [8-13].

In the method of classical dilution, the miscibility is estimated by comparison of the experimental and ideal values of $b_{\mathrm{m}}^{\exp }$ and $[\eta]_{\mathrm{m}}^{\exp }$. The values of $b_{\mathrm{m}}^{\exp }$ and $[\eta]_{\mathrm{m}}^{\exp }$ are determined from a plot of reduced viscosity versus the mixture concentrations $\left\{\eta_{\mathrm{sp}} / c=f(c)\right\}$ (Eq. 1) for solutions containing both polymers:

$$
\frac{\left(\eta_{\mathrm{sp}}\right)_{\mathrm{m}}}{c_{\mathrm{m}}}=[\eta]_{\mathrm{m}}+b_{\mathrm{m}} c_{\mathrm{m}}
$$

where $\left(\eta_{\mathrm{sp}}\right)_{\mathrm{m}}$ is the specific viscosity of the polymer mixture, $b_{\mathrm{m}}^{\exp }$ the experimental value of the viscosity interaction parameter of the polymer mixture, $[\eta]_{\mathrm{m}}^{\exp }$ the experimental value of intrinsic viscosity of the polymer mixture, $[\eta]_{\mathrm{m}}$ the intrinsic viscosity of the polymer mixture and $c_{\mathrm{m}}$ the total concentration of the mixture.

The viscosity interaction parameter $b$ is related to Huggins coefficient $k$ by the equation:

$$
b=k[\eta]^{2}
$$

Krigbaum and Wall [8] have defined the ideal value of the interaction parameter $b_{\mathrm{m}}^{\text {id }}$ by the expression:

$$
\begin{gathered}
b_{\mathrm{m}}^{\mathrm{id}}=b_{\mathrm{AA}} w_{\mathrm{A}}^{2}+b_{\mathrm{BB}} w_{\mathrm{B}}^{2}+2 b_{\mathrm{AB}}^{\mathrm{id}} w_{\mathrm{A}} w_{\mathrm{B}} \\
b_{\mathrm{AB}}^{\mathrm{id}}=b_{\mathrm{AA}}^{1 / 2} b_{\mathrm{BB}}^{1 / 2}
\end{gathered}
$$

where: $b_{\mathrm{AA}}, b_{\mathrm{BB}}, b_{\mathrm{AB}}$ are the interaction parameters of like (AA, $\left.\mathrm{BB}\right)$ and unlike $(\mathrm{AB})$ polymer molecules, respectively, and $w_{\mathrm{A}}$ and $w_{\mathrm{B}}$ are the weight fractions of polymers $\mathrm{A}$ and $\mathrm{B}$, respectively.

The polymer blend is miscible if $\Delta b_{\mathrm{m}}=b_{\mathrm{m}}^{\mathrm{exp}}-b_{\mathrm{m}}^{\mathrm{id}}>0$ and immiscible if $\Delta b_{\mathrm{m}}=b_{\mathrm{m}}^{\mathrm{exp}}-b_{\mathrm{m}}^{\text {id }}<0$.

Garcia et al. [14] defined the ideal value of the interaction parameter, $b_{\mathrm{m}}^{\mathrm{id}}$, as: 


$$
b_{\mathrm{m}}^{\mathrm{id}}=b_{\mathrm{AA}} w_{\mathrm{A}}^{2}+b_{\mathrm{BB}} w_{\mathrm{B}}^{2}
$$

Additionally, Garcia et al. [14] have proposed another miscibility criterion, which is based on the difference between the experimental and ideal values of $[\eta]_{\mathrm{m}}$. If $\Delta[\eta]_{\mathrm{m}}=$ $[\eta]_{\mathrm{m}}^{\text {exp }}-[\eta]_{\mathrm{m}}^{\mathrm{id}}<0$ the system is miscible, and if $\Delta[\eta]_{\mathrm{m}}=[\eta]_{\mathrm{m}}^{\text {exp }}-[\eta]_{\mathrm{m}}^{\text {id }}>0$ the system is immiscible. The value of $[\eta]_{\mathrm{m}}^{\exp }$ is determined from the intercept of the plot according to Eq. 1, whereas $[\eta]_{\mathrm{m}}^{\mathrm{id}}$ is obtained from Eq. 5. The values of $[\eta]_{\mathrm{A}}$ and $[\eta]_{\mathrm{B}}$ are given in Table 1.

$$
[\eta]_{\mathrm{m}}^{\mathrm{id}}=[\eta]_{\mathrm{A}} w_{\mathrm{A}}+[\eta]_{\mathrm{B}} w_{\mathrm{B}}
$$

The aim of this study is to evaluate the miscibility of Ch with PVA and MCCh with PVA on the basis of experimental and ideal values of the viscosity interaction parameters: $b_{\mathrm{m}}$ and $[\eta]_{\mathrm{m}}$, which were calculated from viscosity measurements of dilute solutions. The determination of the miscibility degree of the above polymer pairs has been done by means of two criteria. The influence of molecular weight of $\mathrm{Ch}$ and the degree of PVA hydrolysis on the hydrodynamic properties of blend solutions have also been investigated.

\section{Experimental}

\subsection{Materials}

The physico-chemical characteristics of $\mathrm{Ch}$ and PVA samples are given in Table 1. Distilled water and $0.1 \mathrm{~mol} \cdot \mathrm{dm}^{-3} \mathrm{CH}_{3} \mathrm{COOH} / 0.2 \mathrm{~mol} \cdot \mathrm{dm}^{-3} \mathrm{NaCl}$ were used as solvent. The $\mathrm{pH}=3.25$ at $25^{\circ} \mathrm{C}$ for the polymer solvent. Sodium chloride and acetic acid (analytical reagent grade) were obtained from POCh, Poland.

The viscosity average molecular weight $M_{\mathrm{v}}$ of Ch and PVA was measured with an Ubbelohde viscometer and calculated from the viscosities of the solutions according to the Mark-Houwink-Sakurada equation [17, 18]:

\begin{tabular}{|c|c|c|c|c|c|c|c|c|}
\hline Polymer & $a$ & $\begin{array}{l}K \times 10^{4} \\
\left(\mathrm{dL} \cdot \mathrm{g}^{-1}\right)\end{array}$ & $\begin{array}{l}{[\eta]} \\
\left(\mathrm{dL} \cdot \mathrm{g}^{-1}\right)\end{array}$ & $T(\mathrm{~K})$ & $\begin{array}{l}M_{\mathrm{v}} \times 10^{-3} \\
\left(\mathrm{~g} \cdot \mathrm{mol}^{-1}\right)\end{array}$ & $\begin{array}{l}\text { DD } \\
(\%)\end{array}$ & $\begin{array}{l}\mathrm{DH} \\
(\%)\end{array}$ & Source \\
\hline Ch I & 0.93 & $0.181^{\mathrm{a}}$ & 3.12 & 298 & 427 & 83 & & $\begin{array}{l}\text { Institute of Sea } \\
\text { Fisher (Poland) }\end{array}$ \\
\hline $\mathrm{Ch}$ II & 0.93 & $0.181^{\mathrm{a}}$ & 9.35 & 298 & 1390 & 79 & & Aldrich \\
\hline $\mathrm{MCCh}$ & 0.93 & $0.181^{\mathrm{a}}$ & 7.26 & 298 & 1059 & 84 & & Our laboratory \\
\hline PVA88 & 0.58 & $8.0^{\mathrm{b}}$ & 0.76 & 298 & 136 & & 88 & Loba \\
\hline PVA99 & 0.61 & $6.9^{\mathrm{b}}$ & 0.82 & 298 & 110 & & 99 & Aldrich \\
\hline
\end{tabular}

Table 1 Characteristics of the polymer samples

$a, K$ are the parameters of Mark-Houwink-Sakurada equation, the $M_{\mathrm{v}}$ is the viscosity average molecular weight, $D D$ is the degree of deacetylation of chitosan, $D H$ is the degree of hydrolysis of PVA

a Solvent: $0.1 \mathrm{~mol} \cdot \mathrm{dm}^{-3} \mathrm{CH}_{3} \mathrm{COOH}, 0.2 \mathrm{~mol} \cdot \mathrm{dm}^{-3} \mathrm{NaCl}$ [15]

b Solvent: water [16] 


$$
[\eta]=K \bar{M}_{\mathrm{v}}^{\mathrm{a}}
$$

The temperature of the viscosity measurement, the solvent and the Mark-HouwinkSakurada constants $K$ and $a$ for evaluating $M_{\mathrm{v}}$ are specified in Table 1 .

The degree of deacetylation (DD) of Ch was estimated according to Polish Standards (PN-87/A-86850).

The degree of hydrolysis (DH) of PVA refers to the content of residual vinyl acetate groups. It was determined titrimetrically according to the Japan Industrial Standard [19].

\subsection{Preparations}

Microcrystalline chitosan was prepared in our laboratory from chitosan (Ch II) by means of the original method described in the literature [5]. To the reactor containing $1 \% \mathrm{Ch}$ solution in $1 \%$ aqueous acetic acid was slowly dropped $2 \%$ aqueous sodium hydroxide solution with intensive stirring at room temperature. The subsequent procedure was the same as described earlier [5]. Ch, MCCh and PVA were solubilized, separately, in aqueous $0.1 \mathrm{~mol} \cdot \mathrm{dm}^{-3} \mathrm{CH}_{3} \mathrm{COOH} / 0.2 \mathrm{~mol} \cdot \mathrm{dm}^{-3} \mathrm{NaCl}$ solution and then mixed in different proportions.

\subsection{Viscosity Measurements}

Viscosity measurements of dilute polymer solution $(\mathrm{c}<0.2 \%)$ were carried out in a controlled thermostatic bath at $25 \pm 0.1{ }^{\circ} \mathrm{C}$ using an Ubbelohde capillary viscometer with a viscometer constant of $11.75 \mathrm{~s}^{2}$. Distilled water was used as the calibration fluid for the Ubbelohde viscometer for temperatures in the range $18-30{ }^{\circ} \mathrm{C}$. The flow times were recorded with an accuracy of $\pm 0.01 \mathrm{~s}$. The flow time of each solution was determined as the average of several readings. Before measurement, the solutions were filtered through G1 sintered glass filters. The intrinsic viscosity $[\eta]$, the interaction parameter $b$ and Huggins

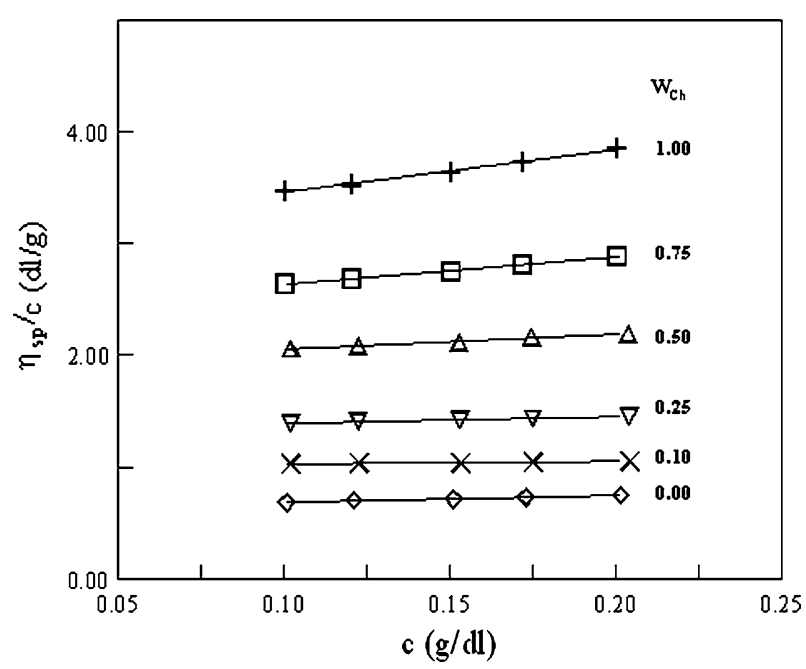

Fig. 1 The reduced viscosity versus polymer concentration for Ch I, PVA(88) and their blends in $0.1 \mathrm{~mol} \cdot \mathrm{dm}^{-3} \mathrm{CH}_{3} \mathrm{COOH}+0.2 \mathrm{~mol} \cdot \mathrm{dm}^{-3} \mathrm{NaCl}$ at $25^{\circ} \mathrm{C} ; \mathrm{w}_{\mathrm{Ch}}$ is the weight fraction of chitosan 
coefficient $k$ values were determined according to the Heller [20] procedure from data obtained for solutions at 5 concentrations. Kinetic energy corrections were taken into account for the evaluation of the intrinsic viscosity, which was determined by extrapolation to infinite dilution (zero solute concentration).

\section{Results and Discussion}

Figures 1, 2 and 3 show the plots of reduced viscosity versus the concentration for $\mathrm{Ch}$, PVA, MCCh and their blends. All the plots show linear behavior in the range of concentration studied, indicating that the intrinsic viscosity can be determined by linear
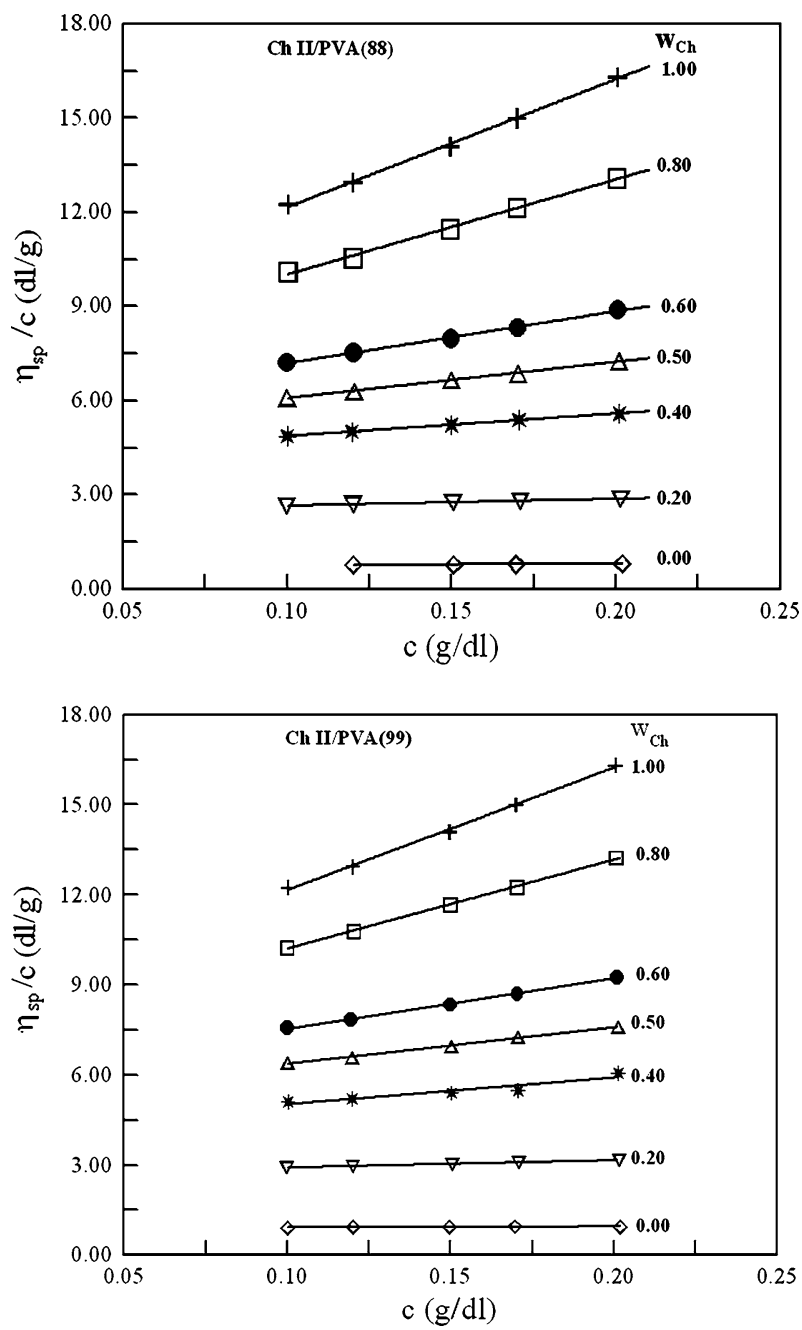

Fig. 2 The reduced viscosity versus polymer concentration for Ch II, PVA [PVA(88) and PVA(99)] and their blends in $0.1 \mathrm{~mol} \cdot \mathrm{dm}^{-3} \mathrm{CH}_{3} \mathrm{COOH}+0.2 \mathrm{~mol} \cdot \mathrm{dm}^{-3} \mathrm{NaCl}$ at $25^{\circ} \mathrm{C}$; $\mathrm{w}_{\mathrm{Ch}}$ is the weight fraction of chitosan 

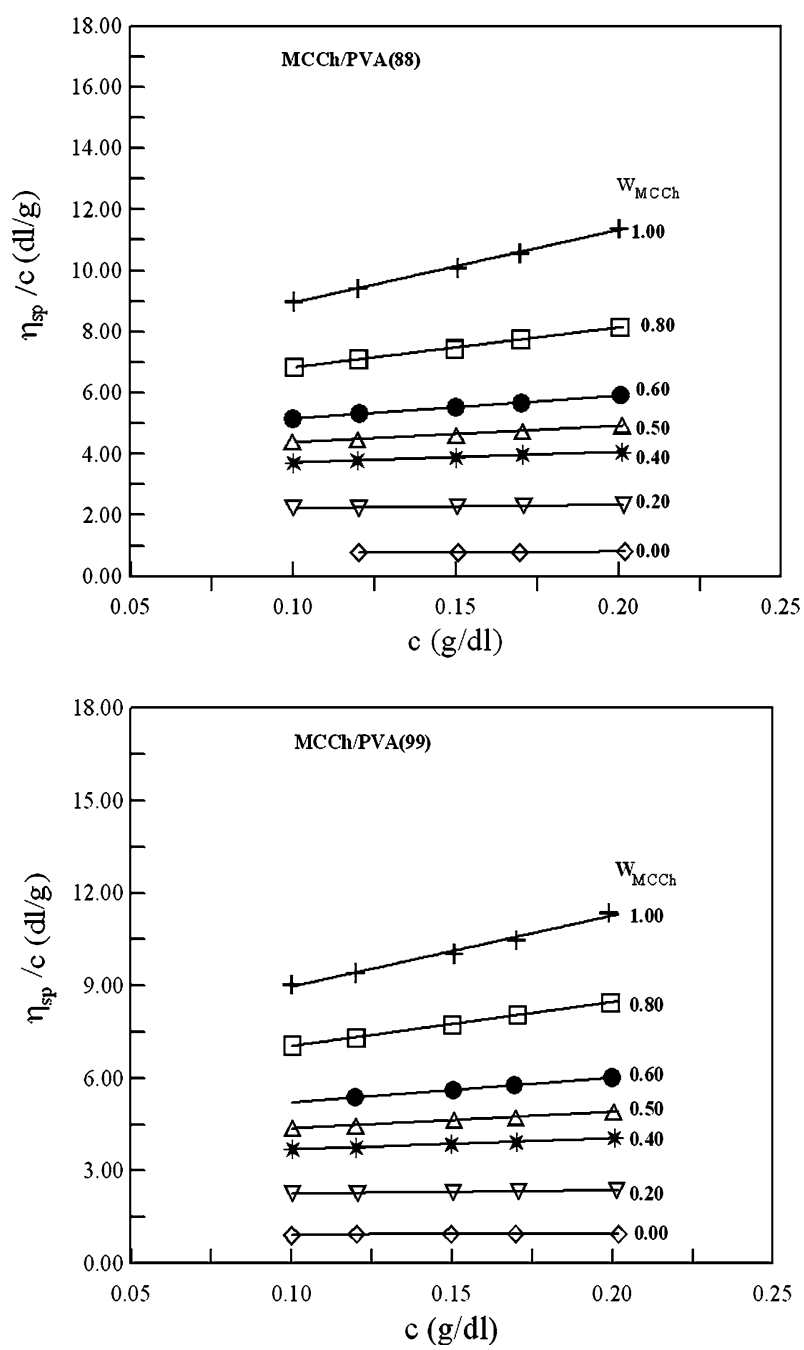

Fig. 3 The reduced viscosity versus polymer concentration for MCCh, PVA [PVA(88) and PVA(99)] and their blends in $0.1 \mathrm{~mol} \cdot \mathrm{dm}^{-3} \mathrm{CH}_{3} \mathrm{COOH}+0.2 \mathrm{~mol} \cdot \mathrm{dm}^{-3} \mathrm{NaCl}$ at $25{ }^{\circ} \mathrm{C}$; $\mathrm{w}_{\mathrm{MCCh}}$ is the weight fraction of microcrystalline chitosan

extrapolation to zero concentration. Ch is a cationic polyelectrolyte and, in aqueous acetic acid solution, in the limit of low ionic strength the electrostatic interactions are weakly screened. Hence, the polyelectrolytic effect of $\mathrm{Ch}$ is observed [21, 22]. In this study, the ionic strength in the investigated system was high enough to prevent the $\mathrm{Ch}$ chains showing a polyelectrolyte effect.

The plots of $\eta_{\mathrm{sp}} / c$ versus $c$ for Ch/PVA and MCCh/PVA blends lies between the plots for the starting polymers. Thus the intermolecular interaction between $\mathrm{Ch} / \mathrm{PVA}$ or $\mathrm{MCCh} /$ PVA is not very strong $[8,9,13,23]$. In Tables 2 and 3 , the values of experimental and ideal intrinsic viscosities are collected for the investigated systems. The $[\eta]_{\mathrm{m}}^{\exp }$ values were obtained according to Heller's procedure [20], which was developed from the inverse of 
Table 2 A comparison of the experimental and ideal viscometric parameters of the $\mathrm{Ch}+\mathrm{PVA}$ blends and dependence on the assumed definition of the ideal values of these parameters

\begin{tabular}{lllllllll}
\hline$w_{\mathrm{ch}}$ & {$[\eta]_{\mathrm{m}}^{\mathrm{exp}}\left(\mathrm{dL} \cdot \mathrm{g}^{-1}\right)$} & {$[\eta]_{\mathrm{m}}^{\mathrm{id}}\left(\mathrm{dL} \cdot \mathrm{g}^{-1}\right)$} & $\Delta[\eta]$ & $b_{\mathrm{m}}^{\exp }\left(\mathrm{dL} \cdot \mathrm{g}^{-1}\right)^{2}$ & $b_{\mathrm{m}}^{\mathrm{id}}\left(\mathrm{dL} \cdot \mathrm{g}^{-1}\right)^{2}$ & $\Delta b_{\mathrm{m}}$ & $b_{\mathrm{m}}^{\mathrm{id}}\left(\mathrm{dL} \cdot \mathrm{g}^{-1}\right)^{2}$ & $\Delta b_{\mathrm{m}}$ \\
\hline Ch I/PVA(88) & & & & & & & \\
0.10 & $0.99 \pm 0.02$ & $0.92 \pm 0.02$ & 0.07 & $0.30 \pm 0.040$ & $0.37 \pm 0.04$ & -0.07 & $0.22 \pm 0.031$ & 0.08 \\
0.25 & $1.33 \pm 0.02$ & $1.28 \pm 0.02$ & 0.05 & $0.67 \pm 0.095$ & $0.65 \pm 0.09$ & 0.02 & $0.33 \pm 0.046$ & 0.34 \\
0.50 & $1.92 \pm 0.03$ & $1.90 \pm 0.03$ & 0.03 & $1.30 \pm 0.180$ & $1.30 \pm 0.18$ & 0.00 & $0.84 \pm 0.120$ & 0.46 \\
0.75 & $2.41 \pm 0.04$ & $2.51 \pm 0.05$ & -0.09 & $2.10 \pm 0.300$ & $2.10 \pm 0.30$ & 0.00 & $1.80 \pm 0.300$ & 0.30 \\
Ch II/PVA $(88)$ & & & & & & & \\
0.20 & $2.45 \pm 0.02$ & $2.48 \pm 0.02$ & -0.03 & $1.85 \pm 0.26$ & $1.79 \pm 0.25$ & 0.06 & $1.12 \pm 0.16$ & 0.73 \\
0.40 & $4.26 \pm 0.04$ & $4.19 \pm 0.05$ & 0.07 & $5.80 \pm 0.81$ & $5.12 \pm 0.72$ & 0.68 & $4.12 \pm 0.58$ & 1.68 \\
0.50 & $5.16 \pm 0.04$ & $5.05 \pm 0.05$ & 0.11 & $8.50 \pm 1.20$ & $7.42 \pm 1.04$ & 1.08 & $6.38 \pm 0.89$ & 2.12 \\
0.60 & $5.96 \pm 0.06$ & $5.91 \pm 0.06$ & 0.05 & $11.4 \pm 1.60$ & $10.2 \pm 1.43$ & 1.20 & $9.15 \pm 1.28$ & 2.25 \\
0.80 & $7.88 \pm 0.07$ & $7.63 \pm 0.08$ & 0.25 & $19.9 \pm 2.79$ & $16.9 \pm 2.37$ & 3.00 & $16.23 \pm 2.27$ & 3.67 \\
Ch II/PVA(99) & & & & & & & \\
0.20 & $2.69 \pm 0.03$ & $2.58 \pm 0.03$ & 0.11 & $2.16 \pm 0.29$ & $2.14 \pm 0.29$ & 0.02 & $1.22 \pm 0.17$ & 0.95 \\
0.40 & $4.33 \pm 0.13$ & $4.27 \pm 0.06$ & 0.06 & $6.38 \pm 0.89$ & $5.55 \pm 0.78$ & 0.83 & $4.17 \pm 0.58$ & 1.38 \\
0.50 & $5.40 \pm 0.06$ & $5.12 \pm 0.07$ & 0.28 & $9.05 \pm 1.27$ & $7.85 \pm 1.10$ & 1.20 & $6.42 \pm 0.90$ & 1.43 \\
0.60 & $6.24 \pm 0.06$ & $6.00 \pm 0.06$ & 0.24 & $11.68 \pm 1.64$ & $10.56 \pm 1.48$ & 1.12 & $9.18 \pm 1.29$ & 2.50 \\
0.80 & $8.08 \pm 0.08$ & $7.66 \pm 0.10$ & 0.42 & $18.94 \pm 2.65$ & $17.16 \pm 2.40$ & 1.78 & $16.24 \pm 2.27$ & 0.92 \\
\hline
\end{tabular}

Solvent: $0.1 \mathrm{~mol} \cdot \mathrm{dm}^{-3} \mathrm{CH}_{3} \mathrm{COOH}+0.2 \mathrm{~mol} \cdot \mathrm{dm}^{-3} \mathrm{NaCl} . b_{\mathrm{m}}^{\text {id }}$ determined according to Krigbaum and Wall [8], $b_{\mathrm{m}}^{\mathrm{id}} \mathrm{d}^{* *}$ determined according to Garcia et al. [14]

$w_{C h}$ the weight fraction of chitosan

Table 3 A comparison of the experimental and ideal viscometric parameters of the MCCh + PVA blends and dependence on the assumed definition of the ideal values of these parameters

\begin{tabular}{|c|c|c|c|c|c|c|c|c|}
\hline$w_{\mathrm{MCCh}}$ & $\begin{array}{l}{[\eta]_{\mathrm{m}}^{\exp }} \\
\left(\mathrm{dL} \cdot \mathrm{g}^{-1}\right)\end{array}$ & $\begin{array}{l}{[\eta]_{\mathrm{m}}^{\mathrm{id}}} \\
\left(\mathrm{dL} \cdot \mathrm{g}^{-1}\right)\end{array}$ & $\Delta[\eta]$ & $b_{\mathrm{m}}^{\exp }\left(\mathrm{dL} \cdot \mathrm{g}^{-1}\right)^{2}$ & $b_{\mathrm{m}}^{\mathrm{id}^{*}}\left(\mathrm{dL} \cdot \mathrm{g}^{-1}\right)^{2}$ & $\Delta b_{\mathrm{m}}$ & $\begin{array}{l}b_{\mathrm{m}}^{\mathrm{id}^{* *}} \\
\left(\mathrm{dL} \cdot \mathrm{g}^{-1}\right)^{2}\end{array}$ & $\Delta b_{\mathrm{m}}$ \\
\hline \multicolumn{9}{|c|}{ MCCh/PVA(88) } \\
\hline 0.20 & $2.11 \pm 0.03$ & $2.05 \pm 0.03$ & 0.06 & $1.03 \pm 0.14$ & $1.26 \pm 0.18$ & -0.23 & $0.73 \pm 0.10$ & 0.30 \\
\hline 0.40 & $3.39 \pm 0.03$ & $3.34 \pm 0.04$ & 0.05 & $3.10 \pm 0.43$ & $3.34 \pm 0.47$ & -0.24 & $2.56 \pm 0.36$ & 0.54 \\
\hline 0.50 & $3.91 \pm 0.04$ & $3.98 \pm 0.04$ & -0.07 & $4.43 \pm 0.62$ & $4.76 \pm 0.67$ & -0.33 & $3.94 \pm 0.55$ & 0.49 \\
\hline 0.60 & $4.51 \pm 0.04$ & $4.63 \pm 0.05$ & -0.12 & $5.89 \pm 0.82$ & $6.43 \pm 0.90$ & -0.54 & $5.64 \pm 0.79$ & 0.25 \\
\hline 0.80 & $5.78 \pm 0.06$ & $5.92 \pm 0.06$ & -0.14 & $9.69 \pm 1.36$ & $10.25 \pm 1.44$ & -0.56 & $9.98 \pm 1.40$ & -0.29 \\
\hline \multicolumn{9}{|c|}{ MCCh/PVA(99) } \\
\hline 0.20 & $2.15 \pm 0.02$ & $2.16 \pm 0.02$ & -0.01 & $0.97 \pm 0.14$ & $1.57 \pm 0.22$ & -0.60 & $0.84 \pm 0.12$ & 0.13 \\
\hline 0.40 & $3.35 \pm 0.03$ & $3.44 \pm 0.04$ & -0.09 & $3.14 \pm 0.44$ & $3.73 \pm 0.52$ & -0.59 & $2.65 \pm 0.37$ & 0.49 \\
\hline 0.50 & $3.90 \pm 0.04$ & $4.08 \pm 0.04$ & -0.18 & $4.41 \pm 0.62$ & $5.17 \pm 0.72$ & -0.76 & $4.03 \pm 0.56$ & 0.38 \\
\hline 0.60 & $4.56 \pm 0.04$ & $4.71 \pm 0.05$ & -0.15 & $6.24 \pm 0.87$ & $6.83 \pm 0.96$ & -0.59 & $5.74 \pm 0.80$ & 0.50 \\
\hline 0.80 & $5.91 \pm 0.06$ & $5.99 \pm 0.06$ & -0.08 & $10.46 \pm 1.46$ & $10.87 \pm 1.52$ & -0.41 & $10.13 \pm 1.42$ & 0.33 \\
\hline
\end{tabular}

Solvent: $0.1 \mathrm{~mol} \cdot \mathrm{dm}^{-3} \mathrm{CH}_{3} \mathrm{COOH}+0.2 \mathrm{~mol} \cdot \mathrm{dm}^{-3} \mathrm{NaCl} . b_{\mathrm{m}}^{\mathrm{id}^{*}}$ determined according to Krigbaum and Wall [8], $b_{\mathrm{m}}^{\mathrm{id}^{* *}}$ determined according to Garcia et al. [14] 
the Huggins and Kraemer equations. This method gives some advantages, including high accuracy of determination of the intrinsic viscosity and slope constants because the slopes of the plots are smaller compared to the slopes of Huggins and Kraemer plots $[11,18,20]$.

The $[\eta]^{\text {id }}$ values were calculated by using Eq. 6. As is seen from Table 2 for $\mathrm{Ch}$ $\mathrm{I}+\mathrm{PVA}(88)$ and Ch II $+\operatorname{PVA}(88)$ blends with $w_{\mathrm{Ch}} \leq 0.6$, the values of $\Delta[\eta]$ are low and marginally exceeded the range of the experimental error. Greater differences in the values of $\Delta[\eta]$ are observed for Ch II + PVA(99) and Ch II + PVA(88) blends with $w_{\mathrm{Ch}}=0.8$ ( $w_{\mathrm{Ch}}$ is the weight fraction of $\mathrm{Ch}$ in the blend). This indicates that the influence of the degree of hydrolysis of PVA on the miscibility of polymeric component is more pronounced than the molecular weight of Ch. Table 2 also shows a comparison of the experimental $b_{\mathrm{m}}^{\exp }$ and the ideal $b_{\mathrm{m}}^{\mathrm{id}}$ viscometric parameters. The ideal values are based on two equations proposed by Krigbaum and Wall [8] (Eq. 3) and Garcia [14] (Eq. 5). For the miscibility criterion of Krigbaum and Wall [8], the $\Delta b_{\mathrm{m}}$ values are positive or zero within the experimental error. In the case of Garcia's criterion [14], the values of parameter $\Delta b_{\mathrm{m}}$ are also positive for all of the investigated systems, exceeding distinctly the range of the experimental error, with the exception of the blend for low content of PVA ( $w_{\mathrm{PVA}} \leq 0.25$ ) in Ch I + PVA(88) and Ch II + PVA(99) blends. So, the Ch + PVA blends satisfy criteria proposed by Krigbaum and Wall [8] and Garcia et al. [14]. This conclusion partially confirmed earlier studies in the solid state [7] where PVA(88) shows partial miscibility with $\mathrm{Ch}$ I. The studies in the solid state were carried out for mixtures obtained from aqueous acetic acid solutions. This may affect the observed differences. It is known that the solvent plays an important role in the miscibility of polymeric compounds [12, 14, 24]. A reasonable interpretation is that in different solvents, the interactions between two different polymers are quite different.

The parameters of the two different miscibility criteria are summarized in Table 3 for MCCh + PVA blends. As can be seen, in the case of the Krigbaum and Wall [8] criterion, the $\Delta b_{\mathrm{m}}$ values are negative for all investigated systems, exceeding the range of the experimental error. Thus, these blends are poorly miscible in solution in comparison with Ch/PVA blends. This is also confirmed by the criterion of Garcia et al. [14], in which the parameters $\Delta b_{\mathrm{m}}$ values are positive but the values are much smaller than for $\mathrm{Ch} / \mathrm{PVA}$ blends. For MCCh/PVA blends with $w_{\mathrm{PVA}} \leq 0.5$, the $\Delta b_{\mathrm{m}}$ values do not indicate deviations beyond the range of experimental error.

\section{Conclusions}

In this paper, the miscibility of dilute aqueous $\mathrm{Ch} \mathrm{I}+\mathrm{PVA}, \mathrm{Ch} \mathrm{II}+\mathrm{PVA}$ and $\mathrm{MCCh}+$ PVA blend solution are investigated. Two different criteria to estimate the polymer-polymer miscibility in dilute solution, the Krigbaum and Wall criterion and Garcia et al. criteria, are considered. As is known, the satisfaction of the miscibility criterion depends on the definition of the ideal parameter values $[11,14]$. If the ideal $b_{\mathrm{m}}^{\text {id }}$ viscometric parameter is defined according to Garcia et al. and Krigbaum and Wall, then the investigated blends of $\mathrm{Ch}+$ PVA blends satisfy the miscibility criterion. Thus, the PVA sample shows miscibility with $\mathrm{Ch}$ at $w_{\mathrm{Ch}}>0.2$. In the case of MCCh + PVA blends, only the Garcia et al. criterion is satisfied. This behavior may indicate a poorer miscibility of the components and stronger repulsive interactions. 
Open Access This article is distributed under the terms of the Creative Commons Attribution License which permits any use, distribution, and reproduction in any medium, provided the original author(s) and the source are credited.

\section{References}

1. Roberts, G.A.F.: Chitin Chemistry, 1st edn. Mac Millan Press Ltd., London (1992)

2. Rinaudo, M.: Review main properties and current applications of some polysaccharides as biomaterials. Polym. Int. 57, 397-430 (2008)

3. Ravi Kumar, M.N.V.: A review of chitin and chitosan applications. React. Funct. Polym. 46, 1-27 (2000)

4. Dutta, P.K., Dutta, J., Tripathi, V.S.: Chitin and chitosan: chemistry, properties and applications. J. Sci. Ind. Res. 63, 20-31 (2004)

5. Struszczyk, H.: Microcrystalline chitosan. I. preparation and properties of microcrystalline chitosan. J. Appl. Polym. Sci. 33, 177-189 (1987)

6. Struszczyk, M.H.: Chitin and chitosan. Part II. Applications of chitosan. Polimery 47, 396-401 (2002)

7. Lewandowska, K.: Miscibility and thermal stability of poly(vinyl alcohol)/chitosan mixtures. Thermochim. Acta 493, 42-48 (2009)

8. Krigbaum, W.R., Wall, F.T.: Viscosities of binary polymeric mixtures. J. Polym. Sci. 5, 505-514 (1950)

9. Cragg, L.H., Bigelow, C.C.: The viscosity slope constant $k^{\prime}-$ Ternary systems: polymer-polymersolvent. J. Polym. Sci. 16, 177-191 (1955)

10. Jiang, W.H., Han, S.J.: An improved criterion of polymer-polymer miscibility determined by viscometery. Eur. Polym. J. 34, 1579-1584 (1998)

11. Lewandowska, K.: The miscibility of poly(vinyl alcohol)/poly(N-vinylpyrrolidone) blends investigated in dilute solutions and solids. Eur. Polym. J. 41, 55-64 (2005)

12. Ren, Y., Yang, R., Liu, X., Liu, F.: Study on miscibility of poly(vinyl chloride) and polyepichlorohydrin by viscometric and thermal analysis. Eur. Polym. J. 47, 2016-2021 (2011)

13. Catsiff, R.E.H., Hewett, W.A.: The interaction of two dissimilar polymers in solution. J. Appl. Polym. Sci. 6, S30-S32 (1962)

14. Garcia, R., Melad, O., Gómez, C.M., Figueruelo, J.E., Campos, A.: Viscometric study on the compatibility of polymer-polymer mixtures in solution. Eur. Polym. J. 35, 47-55 (1999)

15. Roberts, G.A.F., Domoszy, J.G.: Determination of the viscometric constants for chitosan. Int. J. Biol. Macromol. 4, 374-377 (1982)

16. Beresniewicz, A.: The relations between intrinsic viscosity and molecular weight for partially alcoholized polyvinyl acetates. J. Polym. Sci. 39, 63-79 (1959)

17. Flory, P.J.: Principles of Polymer Chemistry, 1st edn. Cornell University Press, Ithaca New York (1953)

18. Bohdanckỳ, M., Kovár, I.: The viscosity of polymer solutions of finite concentration. In: Jenkins, A.D. (ed.) Viscosity of Polymer Solution, vol. 2. Elsevier Science, Amsterdam (1982)

19. Finch, C.A. (ed.): Poly(vinyl alcohol). Wiley, New York (1973)

20. Heller, W.: Treatment of viscosity data on polymer solutions (an analysis of equations and procedures): I. Intrinsic viscosity and limiting slope constants. J. Colloid Sci. 9, 547-573 (1954)

21. Kienzle-Sterzer, C., Rodriguez-Sanchez, D., Rha, Ch.: Dilute solution behavior of a cationic polyelectrolyte. J. Appl. Polym. Sci. 27, 4467-4470 (1982)

22. Chen, R.H., Chen, W.Y., Wang, ShT, Hsu, ChH, Tsai, M.L.: Changes in the Mark-Houwink hydrodynamic volume of chitosan molecules in solutions of different organic acids, at different temperatures and ionic strengths. Carbohydr. Polym. 78, 902-907 (2009)

23. Quadrat, O.: Additivity of the specific viscosities of two polymers as a criterion of their compatibility. Makromol. Chem. Rapid Commun. 1, 651-654 (1980)

24. Pingping, Z., Haiyang, Y., Shiqiang, W.: Viscosity behavior of poly-e-caprolactone (PCL)/poly(vinyl chloride) (PVC) blends in various solvents. Eur. Polym. Sci. 34, 91-94 (1998) 